\title{
Commentary
}

\section{Chhath Puja - A Study in Religious and Cultural Tourism}

\section{Githa Badikilaya*}

Folklore celebrations have ancient origins. Promoting the history, legends, folk songs, rituals and the prasada prepared can be a fascinating exposure contributing towards building tourist attractions. All aspects of folk cultural heritage have a rich tradition that has local stipulations and hence are close to the community members. Having been acknowledged by a community through oral traditions over a period of time, they become obsolete if not documented and promoted thereby ceasing to be of any significance to the later generations. Many times, there is assimilation by other communities as these folk customs are kept simple. One such ancient tradition is the nature and eco friendly festival of Chhath Puja that is celebrated in Eastern Indian States of Bihar, Jharkand, Uttar Pradesh (henceforth UP) and Nepal. Such an eco-friendly form of worship is most relevant in these times when environment degradation and the resultant climate change is a global concern. Also it's a post harvest celebration. In societies that were primarily agricultural and dependent on the sun for life and sustenance, it is no surprise that the sun came to be worshipped not only individually but as a community.

In reality this festival can be called as the Kumbha mela of Bihar as religious fervour is visible on the streets, with the roads paved with religious commerce. Crowds throng with big and small sized offerings on their heads. This is a strange crossroad of tradition and modernity, with modern vehicular traffic intermingling with the

\footnotetext{
* Director and Founder, Destination Heritage; githaub@yahoo.com
} 
walking devotees to the river bank, religious spirituality and rituals, faith and commerce, Bhakti and bargain, Sun God and water and an immense variety of seasonal produce. It is time to introspect, why Chhath Puja is celebrated and sacred to the Biharis?

A sense of gratitude for the five elements and ancestral worship is the base to Chhath Puja that is celebrated on the $6^{\text {th }}$ day or Shast $i$ (sixth). It is celebrated twice - in regional calendars, karthik (Oct/Nov) and chaitra (April). It's a festival worshipping the sun God, dawn goddess Usha fondly referred as, Chhath Maayi and river Ganga without the intervention of the priest with the chanting of mantras for 20 minutes. The last element is a new phenomenon as earlier it was performed only through folk songs. The prayers are offered to the setting and rising sun in the following day. The rituals are thus very simple with the offerings in a sooyi or winnow. It starts with the cleaning of the river ghats, including smaller water body ghats by the government. Elaborate arrangements for the safety of the devotees are also ensured during this time. The festival is based on the idea of cleansing the body and mind and the surroundings.

The devotees fast for two days at least without drinking water for the fulfilment of vows and thanking the bounty of the Sun. Some devotees in the villages stand in the water at least for two hours and offer prasada and arghya (water pouring from the hands and also milk) to sun. What one can also witness is that every family member does the arghya and the process may take a minimum of half an hour. The morning arghya is an expression of gratitude for a bountiful harvest, peace and prosperity in the New Year and the evening arghya is for the benevolence of the Sun God. The standing devotee facing East takes rounds while offering the prasada. The river comes alive with sparkling of thousands of lit earthen lamps. When a vow made for begetting children is fulfilled, the puja also is offered to a clay idol of an elephant. One can see devotees rolling on the ground including small children while making a wish. This is known as Buniya Bari.

It is mainly the women who carry forward and keep traditions alive and this festival too is no exception, though some men also perform the austerities to keep the traditions alive when the mother is not able to perform the puja. As such this celebration is passed on 
through generations. It can be stopped if there was a death in the family. If for some reason it is discontinued (other than death) it cannot be resumed again, thereby giving a religious sanctity to this simple festival. Sharad an artist from Darbhanga but residing in Patna informs that the devotees believe that if the huge Prasada basket carried by the male devotees falls down on their way home, it portends severe consequences in the coming year.

The offerings include sweets, rice porridge, Thekua, (a hard wheatbased cake sweetened with jaggery) prepared on the third day are usually cooked on traditional earthen ovens called 'chulhas' and mango wood is used as fuel. Rice laddu, fruits like sugarcane, sweet lime and banana, cotton thread, areca nut, cloves, turmeric, sweet potato and ginger are the other offerings in the winnow. Moreover, only bronze or clay vessels are used making it a wholly an eco friendly festival. Thus all the items grown or used are from the site itself and nothing sourced from outside. In fact, the flour mills are cleaned solely for making flours for the Puja. During the fast, only leafy vegetables, pumpkin, and radish are consumed as these vegetables are considered pure and satvic and easily digestible. The food is strictly vegetarian and is cooked without salt, onions or garlic thereby maintaining the purity of the offering to the gods.

Nahay Khay- As the very name indicates, it is bathe and eat. On the first day of Chhath Puja, devotees take a dip, and carry home the holy water to prepare the offerings. They make porridge from raw rice.

Lohanda-On the second day, the devotees observe a fast that ends in the evening after sunset. On this day, the offerings prepared are kheer, puris and bananas that they distribute to the neighbours as well. After consuming the offering, the fast continues for the next 36 hours. Devotees break their fast by taking a bite of ginger and sugar. They brush their teeth with mango/neem twig in the evening and few break their fast with preparation made out of pumpkin and kheer made of jaggery and puris, puffed flour cakes that are deep fried. This becomes a celebratory meal.

Sandhya Arghya (evening offerings)-After preparing the prasada which takes up the whole day, the devotees take a dip in the water body in the evening and worship the setting sun with offerings and 
folk songs. The whole family accompanies the devotee to the water source. On the ghat, the lamps are kept under a canopy of five sugarcane sticks signifying the Pancha mahabhutas (5 elements, that is, earth, water, air, fire, ether) as the primal source of human existence (Earth, water, fire, air and ether or sky). This is known as Kasi bharna. The lighted lamps signify the sun sustaining the life itself. This is the most important day of this festival. Devotees during this period observe a strict regimen of sleeping on the floor and live frugally and this is the main festival day. We can see people taking baskets of Prasada on their heads to offer to Chath maiyya (chhath mother) and some have sugarcane fronds on their shoulders.

Usha Arghya-The fourth day sees the devotees giving offerings to the rising sun. They gather from early morning. They break their fast after the same.

Many devotees are however unaware of the historical and cultural background but fully aware of the mythology and tales and believe strongly that their wishes will be fulfilled.

Like every other Indian festival, Chhath Puja traverses on a rich fare of mythology and legends. There is a reference to this festival in both the Epics and Puranas. In the Ramayana, Sita performed Chhath vrata on returning to Ayodhya after Deepawali. Having observed the norms strictly, she was blessed with twins. In Mahabharata, it was performed by Kunti and Draupadi after they escaped from the lac house. This Chhath Puja was observed by warrior Karna, the son of Surya, renowned for his charitable nature. Since Karna became powerful by observing Surya Puja, select sects of Hindus also worship the Sun as a deity symbolising courage and prosperity. According to the Brahmavaivarta Purana, when God created the world, he also created the duality of Purusha and Prakriti. Prakriti was then further divided into several elements, of which the sixth part is Chhathi/Shasthi. She is called Devasena, says Pradyumna Kumar, an award-winning Madhubani artist, who has extensively researched Chhath Puja. Devasena is associated with children. Another reference to Chhathi Mai as the giver and protector of children comes in K.S. Singh's paper (1998) solar traditions in tribal and folk cultures of India. He writes: "The kathas, as they are recited today, also bear evidence of the influence 
of many other cults, such as that of the mother goddess who is called Chhathi Mai. The influence of the mother goddess cult on Chhath may have appeared later".

From literature, once can understand that in bygone times our sages dwelling in the forest performed austerities without any intake of solid or liquid diet i.e. fasting seen in many of our festivals. Akin to the practice is Chhath Vrata.

Many sun temples have been built in India since the second century BC. The sun temples of Bihar prominently at Deo in Aurangabad and Baragaon near Nalanda, come to life buzzing with activity on Chhath Puja. The cult of sun worship has been prevalent throughout the world for centuries as Sun was considered as a universal force. The origins of Sun worship date back to the Bronze Age. The sun is represented in Neolithic pottery in PiklihaLingsaur Diatrict of Uttara Karnataka, as well as rock paintings in Chhatisgarh. However, the revival and large scale worship of the sun god in the fourth/fifth century started in the Gupta period credited largely to the powerful sect of Sourya sect. It later merged into Vaishnavism. However, sun worship is still practiced among the numerous tribes of India, especially in Odisha. It is still homage for the bountiful harvest, marriages and birth.

Cultural tourism has been defined by UNWTO as "the movement of persons to cultural attractions away from their normal place of residence, with the intention to gather new information and experiences to satisfy their cultural needs". Cultural tourism is experiencing a transformation in the tourism sector in India and is fast poised to making it as a brand for a different experiences in a sustainable manner that also aids in safeguarding the timeless heritage of communities. There is an interest among the young affluent travellers to soak in the cultural heritage of a place as it's opportune to interact with the local community, to learn or experience firsthand the local culture. When the significance is understood, the trip becomes meaningful. Festival tourism constitutes a fast growing leisure, business, and tourism-related phenomena and tourism boards across the world have used festivals for generating opportunities to promote tourism. This should not be difficult if all the states package and promote their cultural tourism in a diverse country as India, more so as there are 
festivals throughout the year for every season and harvesting time of the astronomical happenings coupled with the joie de verve speckled with colours, music, folk dances and songs.

Festival Tourism in their diversity, also engage both artists, locals and visitors as participants partaking the specific cultural perceptions arising from history, culture, customs and tradition for a memorable experience. Food/culinary festivals as part of the festival tourism has great potential as local produce and cuisine are predominant. But attention is to be paid to preserve their authenticity. The heritage can be perceived as linked to a collective social memory which lends to the construction of the nation's common legacy and identity. This becomes attractive for a tourist and worthwhile to visit the place as they get aquatinted with another culture.

In this age of globalization, the international and the multinational often win the race. Homogenising is another concern in contemporary times. Local, cultural traditions and perspectives deserve acknowledgement and support from the tourism industry. It is here that celebrating Festival Tourism, that the indigenous and ethnicity could be maintained as a collective venture.

\section{References}

Singh, K. S. (Ed.). (1998). People of India: Rajasthan (Vol. 38). Popular Prakashan.

World Tourism Organization. (2018). Tourism and Culture Synergies. UNWTO, Madrid, DOI: https://doi.org/10.18111/9789284418978 